\title{
The COMET Initiative database: progress and activities update (2015)
}

\author{
E. Gargon ${ }^{1 *}$, P. R. Williamson ${ }^{1}$, D. G. Altman², J. M. Blazeby ${ }^{3}$, S. Tunis ${ }^{4}$ and M. Clarke $^{5}$
}

\begin{abstract}
This letter describes the substantial activity on the Core Outcome Measure in Effectiveness Trials (COMET) website in 2015, updating our earlier progress reports for the period from the launch of the COMET website and database in August 2011 to December 2014. As in previous years, 2015 saw further increases in the annual number of visits to the website, the number of pages viewed and the number of searches undertaken. The sustained growth in use of the website and database suggests that COMET is continuing to gain interest and prominence, and that the resources are useful to people interested in the development of core outcome sets.
\end{abstract}

Keywords: Core outcome set, Database, Resources

\section{Correspondence/findings \\ Background}

As the New Year bells were ringing and the fireworks were exploding to welcome 2016 in cities such as Fray Bentos in South America, an Internet user in Tianjin, China ran the 10,000th search of the Core Outcome Measures in Effectiveness Trials (COMET) database. They were looking for information about non-small-cell lung cancer (NSCLC), and will have been shown details of two core outcome sets (COS) recently added to the database $[1,2]$. This letter describes the substantial activity on the COMET website [3] in the 365 days before that search. We update our earlier progress since the launch of the COMET website and database in August 2011 to December 2014 $[4,5]$.

\section{Activity and content}

A total of 720 studies relevant to the development of COS were included in the COMET database at the end of December 2015, with 147 added during the year. This included 32 reports relating to 29 COS identified in the most recent update to the systematic review of COS [2], which had originally been performed in 2013 [1].

As in previous years, 2015 saw further increases in the annual number of visits to the website (Table 1) and

\footnotetext{
* Correspondence: e.gargon@liv.ac.uk

${ }^{1}$ Department of Biostatistics, University of Liverpool, 1st floor Duncan

Building, Daulby Street, Liverpool L69 3GA, UK

Full list of author information is available at the end of the article
}

although the proportional change declined in 2015, the absolute numbers continue to increase. For instance, the proportional increase in new visitors from 2014 to 2015 was $33 \%$, compared to $43 \%$ for 2013 to 2014; but the absolute increase from 2014 to 2015 was 3269 compared to 2936 for 2013 to 2014. Most visitors to the website arrived either via links following an organic search using a search engine, such as Google (68\%), or direct $(20 \%)$ (Fig. 1). However, new for 2015, were arrivals from links in emails, which is in large part attributable to the move of the COMET newsletter from a PDF format to an email format.

Social media also leads many people to the website and Twitter accounted for $89 \%$ of social referrals to the COMET website in 2015 (Table 2). The COMET Twitter account is monitored by the research team and tweets are sent when new COS papers are published, to announce relevant presentations at conferences and to retweet COS-related tweets from others that we follow. The COMET account has more than 1300 followers and the Twitter page links to the COMET website.

The highest proportions of referrals were from the Core Outcomes in Women's Health (CROWN) Initiative (10\%), the University of Liverpool (6\%), Trials journal (5\%), MRC Hubs for Trials Methodology Research (5\%), Cochrane Canada (5\%) and the Standard Protocol Items: Recommendations for Interventional Trials (SPIRIT) 
Table 1 Core Outcome Measures in Effectiveness Trials (COMET) website usage statistics 2012 to 2015

\begin{tabular}{|c|c|c|c|c|c|c|c|c|c|c|c|c|c|c|c|c|}
\hline \multirow[b]{2}{*}{ Year } & \multicolumn{4}{|c|}{ Number of visits } & \multicolumn{4}{|c|}{ Number of unique visitors } & \multicolumn{4}{|c|}{ Number of new visitors } & \multicolumn{4}{|c|}{ Number of searches } \\
\hline & 2012 & 2013 & 2014 & 2015 & 2012 & 2013 & 2014 & 2015 & 2012 & 2013 & 2014 & 2015 & 2012 & 2013 & 2014 & 2015 \\
\hline Total & 7982 & 12332 & 16768 & 20952 & 5471 & 8369 & 12257 & 15366 & 4611 & 6844 & 9780 & 13049 & 1597 & 2139 & 2383 & 3411 \\
\hline Increase per year (\%) & $\mathrm{n} / \mathrm{a}$ & $55 \%$ & $36 \%$ & $25 \%$ & $\mathrm{n} / \mathrm{a}$ & $53 \%$ & $47 \%$ & $25 \%$ & $\mathrm{n} / \mathrm{a}$ & $48 \%$ & $43 \%$ & $33 \%$ & $\mathrm{n} / \mathrm{a}$ & $34 \%$ & $11 \%$ & $43 \%$ \\
\hline $\begin{array}{l}\text { Overall increase from } 2012 \\
\text { to } 2015 \text { (\%) }\end{array}$ & \multicolumn{4}{|c|}{$163 \%$} & \multicolumn{4}{|c|}{$181 \%$} & \multicolumn{4}{|c|}{$183 \%$} & \multicolumn{4}{|c|}{$114 \%$} \\
\hline
\end{tabular}

initiative (4\%). CROWN is an international initiative to harmonise outcome reporting in women's health research. More than 70 journals have committed to encouraging the development and reporting of COS in this area and CROWN advises all COS developers to register with COMET [6]. Trials has published several COS papers which generated referrals to the COMET website, including 'Developing core outcome sets for clinical trials: issues to consider' [7], the special collection of the meeting proceedings and abstracts from the 4th COMET meeting in Rome in November 2014, and the report of the first meeting to discuss Trial Forge [8]. The 5th COMET meeting was jointly hosted with Cochrane Canada in Calgary in May 2015, hence the large number of referrals from Cochrane Canada, and the more than doubling in the annual number of visits from Canada, from 624 in 2014 to 1449 in 2015 (Table 3). The referrals from SPIRIT reflect that initiative's encouragement of trial investigators to consider measuring the outcomes in a COS in their trial as part of their effort to improve the quality of clinical trial protocols by defining an evidence-based set of items to address in a protocol.

In 2015 , there were a total 80,799 page views, a $10 \%$ increase from 73,617 in 2014. Analyses of the COMET website data show that $56 \%$ of visitors went beyond the page on which they landed in 2015, similar to 2014 and, as in previous years, the most common first interaction was to search the COMET database. Other first interactions included moving to the overview of the COMET Initiative, accessing the database without completing a search, and checking the resources page. This Core Resource Pack is once again the second most highly accessed resource on the website (after the database), with 1372 page views in 2015, compared to 1064 in 2014 (29\% increase).

The total number of visits increased by $25 \%$ in 2015 compared to 2014.The number of unique visitors also increased by $25 \%$, and the number of new visitors increased by $33 \%$. Full details are provided in Table 1 . Visitors came from 127 countries, with $53 \%$ of visits now coming from outside the UK, an increase of $2 \%$ from $8565 / 16,768$ in 2014 to $11,090 / 20,952$ in 2015 (Table 3).

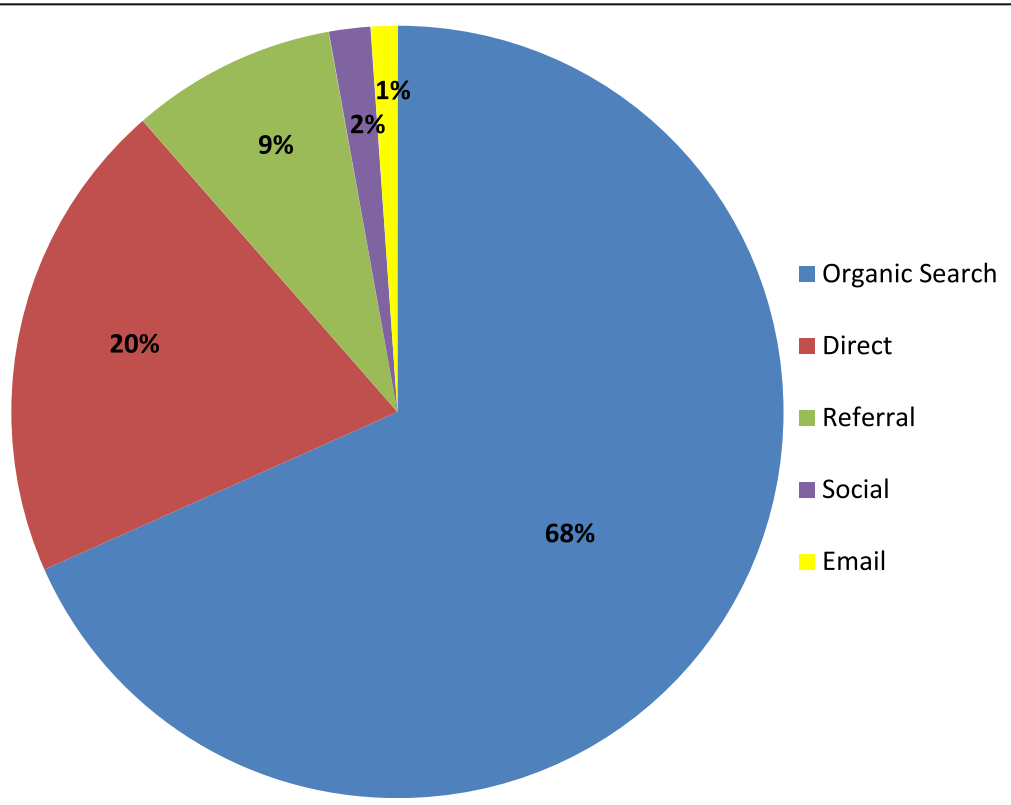

Fig. 1 Core Outcome Measures in Effectiveness Trials (COMET) website acquisition overview 
Table 2 Examples of Twitter referrals

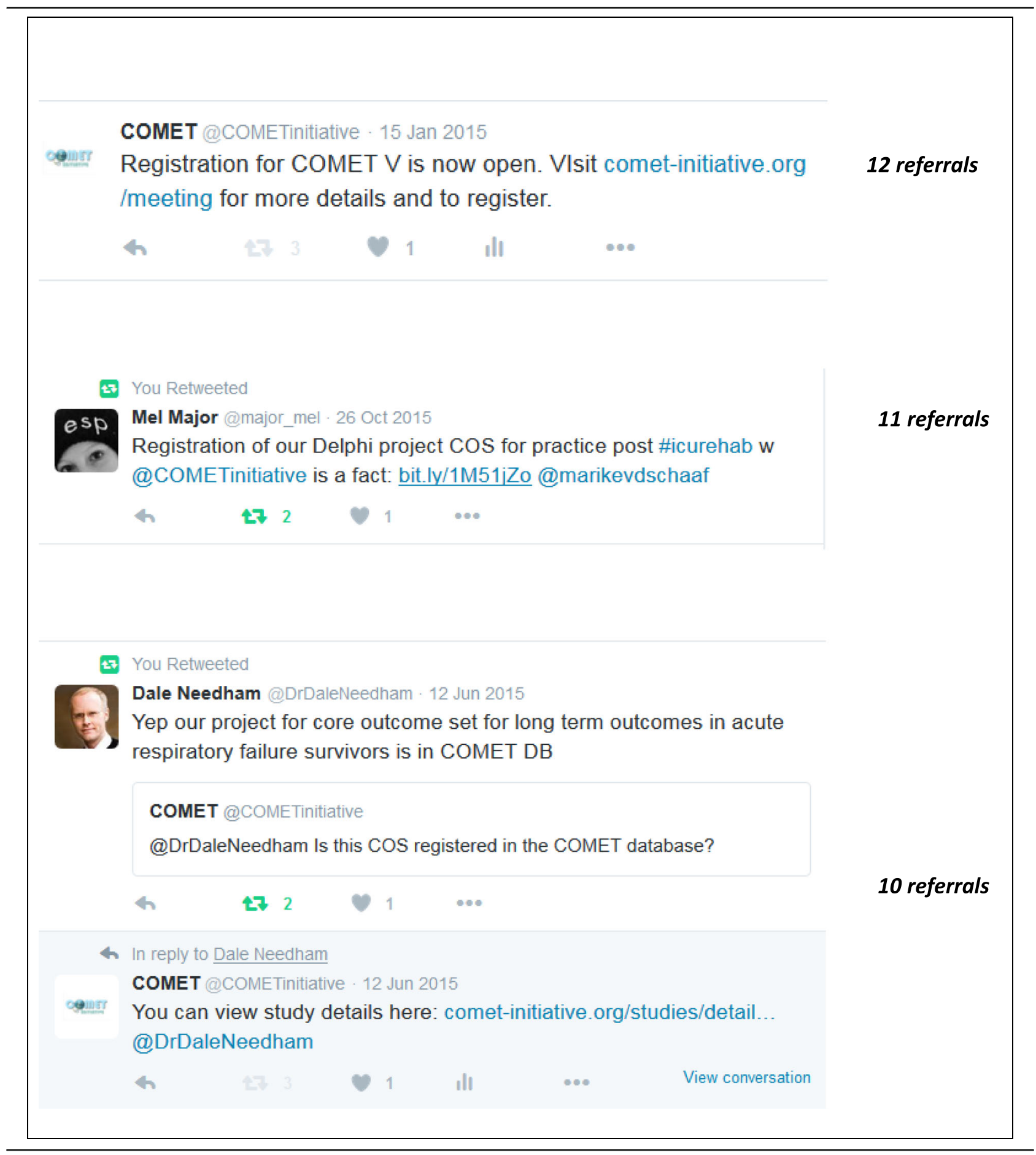

By the end of December 2015 in the time zone of the COMET website, a total of 9999 searches had been undertaken in the COMET database, with 3411 in 2015 alone (a 43\% increase from 2014). The most frequently used search criteria were consistent with previous years with the most frequently searched category being Disease Category. The 'top 10' searched for terms are shown in Table 4. In 2014, the most commonly searched term was 'cancer' $(n=129)$ and although this increased to 137 searches in 2015, it was superseded in 2015 by 'pregnancy and childbirth' $(n=193)$. 
Table 3 Countries with the most visits to the Core Outcome Measure in Effectiveness Trials (COMET) website in 2012 to 2015

\begin{tabular}{|c|c|c|c|c|c|c|c|}
\hline 2012 & & 2013 & & 2014 & & 2015 & \\
\hline United Kingdom & 5577 & United Kingdom & 7526 & United Kingdom & 8203 & United Kingdom & 9862 \\
\hline United States & 431 & United States & 1022 & United States & 2038 & United States & 2444 \\
\hline Canada & 326 & Canada & 501 & Italy & 1115 & Canada & 1449 \\
\hline Australia & 201 & Australia & 321 & Canada & 624 & Australia & 654 \\
\hline Germany & 186 & Italy & 315 & Germany & 581 & France & 593 \\
\hline Netherlands & 166 & Netherlands & 308 & Netherlands & 510 & Netherlands & 570 \\
\hline Italy & 161 & Germany & 285 & Australia & 494 & Germany & 553 \\
\hline France & 125 & Japan & 228 & France & 374 & India & 477 \\
\hline Ireland & 113 & France & 227 & India & 306 & Italy & 439 \\
\hline Norway & 62 & Ireland & 159 & Ireland & 239 & Ireland & 415 \\
\hline
\end{tabular}

In 2015, we conducted a pop-up survey to find out why people were searching in the COMET database. The survey appeared at the beginning of each search during a 1-month period, asking people to select single response to give their reason for searching in the COMET database. Full details of the survey have been published [2] but, in summary, it showed that the most common reasons for searching the database were to inform decision-making about developing a COS, or to inform the outcomes in planning a clinical trial. The popup survey also confirmed the importance of keeping the contents of the database up to date, if it is to help researchers to avoid unnecessary duplication of effort and minimise waste [9].

The sustained growth in use of the website and database suggests that COMET is continuing to gain interest and prominence, and that the resources are useful to people interested in COS development. To help ensure that the content is kept up to date a second update of the systematic review of COS $[1,2]$ is underway and the COMET website and database usage figures will continue to be monitored and assessed annually.

Table 4 'Top 10' search terms in 2015

\begin{tabular}{ll}
\hline Category & Number \\
\hline Pregnancy and childbirth & 193 \\
Cancer & 137 \\
Neurology & 88 \\
Mental health & 79 \\
Gynaecology & 77 \\
Skin & 76 \\
Heart and circulation & 69 \\
Anaesthesia and pain control & 68 \\
Dentistry and oral health & 65 \\
Orthopaedics and trauma & 65 \\
\hline
\end{tabular}

\section{Abbreviations}

COMET: Core Outcome Measures in Effectiveness Trials; COS: Core outcome set(s); CROWN: Core Outcomes in Women's Health; NSCLC: Non-small-cell lung cancer; SPIRIT: Standard Protocol Items: Recommendations for Interventional Trials

\section{Acknowledgements}

Ms. Mel Major, Associate Professor Marike vander Schaaf and Professor Dale Needham consent for their Twitter profiles and tweets to be used in this manuscript.

\section{Funding}

This work was supported by the MRC North West Hub for Trials Methodology Research (MR/K025635/1), and the NIHR Senior Investigators Award (NF-SI_0513-10025).

\section{Availability of data and materials}

Not applicable (but data used to prepare the tables is available from the authors).

\section{Authors' contributions}

EG and MC conceived the idea for these periodic reports. EG performed the analysis. EG, PW, MC, JB, ST and DA interpreted data. EG wrote the manuscript. All authors read and approved the final manuscript.

\section{Competing interests}

DA, JB, MC, ST and PW are members of the COMET Management Group and coapplicants on grants to support COMET and related work. EG is a member of the COMET Management Group and is the COMET project coordinator.

\section{Consent for publication}

Not applicable.

\section{Ethics approval and consent to participate}

Not applicable.

\footnotetext{
Author details

'Department of Biostatistics, University of Liverpool, 1st floor Duncan Building, Daulby Street, Liverpool L69 3GA, UK. ${ }^{2}$ University of Oxford, Centre for Statistics in Medicine, Botnar Research Centre, Windmill Road, Oxford OX3 7LD, UK. ${ }^{3}$ School of Social and Community Medicine, University of Bristol, Canynge Hall, 39 Whatley Road, Bristol BS8 2PS, UK. ${ }^{4}$ Center for Medical Technology Policy (CMTP), World Trade Center Baltimore, 401 East Pratt Street, Suite 631, Baltimore, MD 21202, USA. ${ }^{5}$ Queen's University Belfast, Institute of Clinical Sciences, Block B, Royal Hospitals, Grosvenor Road, Belfast BT12 6BJ, UK.

Received: 25 May 2016 Accepted: 9 January 2017 Published online: 03 February 2017
} 


\section{References}

1. Gargon E, et al. Choosing important health outcomes for comparative effectiveness research: a systematic review. PLoS One. 2014;9(6):e99111.

2. Gorst SL, et al. Choosing important health outcomes for comparative effectiveness research: an updated review and user survey. PLoS One. 2016;11(1):e0146444.

3. COMET. Core Outcome Measures in Effectiveness Trials. Available from: www.comet-initiative.org. Accessed 27 Jan 2017.

4. Gargon $E_{\text {, et }}$ al. The COMET Initiative database: progress and activities from 2011 to 2013. Trials. 2014;15(1):279.

5. Gargon E, et al. The COMET Initiative database: progress and activities update (2014). Trials. 2015;16(1):515.

6. Khan K. The CROWN Initiative: journal editors invite researchers to develop core outcomes in women's health. J Ovarian Res. 2015;8(1):6.

7. Williamson PR, et al. Developing core outcome sets for clinical trials: issues to consider. Trials. 2012;13(1):132.

8. Treweek $\mathrm{S}$, et al. Making randomised trials more efficient: report of the first meeting to discuss the Trial Forge platform. Trials. 2015;16:261.

9. Ioannidis JPA, et al. Increasing value and reducing waste in research design, conduct, and analysis. Lancet. 2014;383(9912):166-75.

Submit your next manuscript to BioMed Central and we will help you at every step:

- We accept pre-submission inquiries

- Our selector tool helps you to find the most relevant journal

- We provide round the clock customer support

- Convenient online submission

- Thorough peer review

- Inclusion in PubMed and all major indexing services

- Maximum visibility for your research

Submit your manuscript at www.biomedcentral.com/submit
Biomed Central 